\title{
Maternidades y crianzas en el Movimiento Campesino de Santiago del Estero - Vía Campesina (Argentina)
}

\section{Mariela Pena}

Universidad de Buenos Aires

marielapena6@gmail.com

\section{RESUMEN}

La cuestión de la diversidad en las formas de asumir la maternidad, así como de los costos físicos y emocionales invisibilizados que recaen sobre las mujeres, viene siendo problematizada por los estudios feministas, que han demostrado la relevancia de abordar el problema desde distintas perspectivas y contextos. Aqui exploro el interrogante en torno a la heterogeneidad de sus sentidos y de los modos de crianza a partir de un estudio etnográfico del caso del Movimiento Campesino de Santiago del Estero - Vía Campesina de Argentina, una organización mixta que se propone crear un modo de vida en contraposición al individualismo capitalista en todos los planos de la vida social.

Sugiero que, las mujeres campesinas organizadas, en tanto sujetas políticamente activas, resignifican la maternidad como práctica de defensa de un modo de vida amenazado, y la consideran parte de sus procesos de construcción identitaria y de dignificación. A su vez, son conscientes de las limitaciones para concretar dichos ideales en las prácticas comunitarias y, por lo tanto, ponen en acción modificaciones vinculadas mayoritariamente con la redistribución de las tareas domésticas y de crianza. Las maternidades no elegidas, por otra parte, continúan siendo un asunto dificil de tratar al interior de la organización.

Palabras clave: mujeres campesinas, movimiento social, maternidad, género, crianza. 


\section{Motherhood and upbringing in the Peasant Movement of Santiago del Estero-Vía Campesina (Argentina)}

\section{ABSTRACT}

The diversity of ways of assuming motherhood, as well as the invisible physical and emotional costs that fall on women, have been problematized by feminist studies. These have shown the relevance of addressing the problems from different perspectives and contexts. In this article, I explore the heterogeneity of meanings and different ways of upbringing through an ethnographic case study of the Peasant Movement of Santiago del Estero - Via Campesina of Argentina. Via Campesina is a mixed organization that aims to create a way of life opposed to capitalist individualism, on every level of social life. I argue that organized peasant women -therefore politically active subjects- redefine motherhood as a practice of defending a threatened way of life, and consider it a part of their processes of identity construction and dignification. At the same time, they were aware of the limitations that affect the realization of these ideals in community practices. They, therefore, put into action modifications linked to the redistribution of domestic and upbringing tasks. Unchosen motherhood, on the other hand, continues to be a difficult issue within the organization.

Keywords: peasant women, social movement, motherhood, gender, upbringing. 


\section{INTRODUCCIÓN}

Este trabajo se inscribe en el debate, dentro de los estudios feministas, en torno a los sentidos heterogéneos que puede cobrar la maternidad para las mujeres contemporáneas en contextos disímiles, así como las continuidades y rupturas en las formas de cuidado y crianza.

Esta cuestión es explorada a partir de un estudio de caso, con perspectiva etnográfica, centrado en las mujeres que integran el Movimiento Campesino de Santiago del Estero (MOCASE), de la región centro-norte de la Argentina, el cual a su vez se integra en la organización global Vía Campesina.

El MOCASE - Vía Campesina es un movimiento social rural y mixto, conformado en la década de 1990 a partir de conflictos coyunturales sobre la tenencia y propiedad de las tierras. La disputa ocurre entre pobladores locales y sectores empresarios (con la complicidad del poder político y económico local), interesados en la región debido a la ampliación nacional de lo que se conoce como «la frontera sojera»; es decir, al aumento de terrenos disponibles para la plantación de la soja y otras producciones agroexportables mediante modificaciones transgénicas y tecnológicas.

Mientras que este proceso ha provocado severas modificaciones en términos ecológicos ${ }^{1}$, también ha afectado seriamente las condiciones de vida de la pobla-

\footnotetext{
Este proceso ha acentuado los desmontes, talas y deforestaciones provocando lo que actualmente se evidencia como incipiente desertificación, modificaciones en la composición de los suelos (elevados niveles de salitre y arsénico) y el raleado de la vegetación (Durand, 2006; Díaz Estévez, 2005; Barbetta y Lapegna, 2004). Con respecto a la fauna local, campesinos y campesinas locales que acostumbraban la práctica de la caza periódica para la autosubsistencia han denunciado que en sus territorios han desaparecido varias especies nativas (yaguares, tapires, osos hormigueros, especies de aves y monos, entre otros) y que muchos otros animales son actualmente más raros de ver (pumas, tortugas terrestres, zorros, gatos monteses) (autor, notas de campo).
} 
ción local, que tradicionalmente sobrevivía a partir de estrategias de vida que combinaban los distintos y escasos recursos disponibles, tales como el cultivo de alimentos (limitado debido a las características de los suelos) y el pastoreo de cabras con actividades productivas extraprediales para la industria ferroviaria o algodonera, en condiciones de explotación (Durand, 2006; De Dios, 2009). De modo que, originalmente, la organización campesina $\mathrm{MOCASE}^{2}$ surge como forma de defensa legal, territorial y política.

Para los fines de este análisis, cabe resaltar que actualmente el MOCASE Vía Campesina cuenta con una trayectoria política de más de veinticinco años en la cual, además de desarrollar formas de resistencia en el territorio ${ }^{3}$, ha logrado articular una identidad propia en tanto campesinos, basada en los ejes de territorialidad, de utilización sostenible de los recursos naturales, de vínculos comunitarios solidarios y de formación política basada en la educación popular (Michi, 2010). Sobre estos criterios se ha conformado un modo de vida alternativo que se opone al modelo de desarrollo capitalista, a la propiedad privada y al individualismo, defendiendo valores y prácticas alternativas que se llevan a cabo desde todos los ámbitos de la vida social.

Así, esta construcción colectiva resulta transformadora no solo en cuanto al plano material o económico sino en torno a las identidades y a las subjetividades de campesinos y campesinas (Barbetta, 2009). A partir de estas consideraciones, desde 2015 vengo desarrollando un estudio - del cual este artículo se desprende- - que analiza la distribución de recursos y sentidos según el género al interior del movimiento (Pena, 2017a) a partir del estudio de las emociones (Jaspers, 2012) y su interlocución con los feminismos prevalecientes en la región latinoamericana (Pena, 2017b).

La problemática de las maternidades, que me ocupa ahora, se enmarca de este modo en la pregunta por el impacto y las posibilidades que genera la acción colectiva (Melucci, 1996) creada por la organización social que tratamos, de cara a los intereses de las mujeres y sus subjetividades.

En este sentido, este trabajo busca aportar conocimiento sobre las condiciones de vida reales en las cuales se enmarcan la crianza y la maternidad en el

Referimos a trabajos de este y otros autores para no redundar en la información disponible (Pena, 2017a; 2017b, Barbetta, 2009; Durand, 2006; Díaz Estévez, 2005; Michi, 2010).

Actualmente, los campesinos y campesinas organizados como Movimiento Campesino de Santiago del Estero - Vía Campesina (MOCASE-VC) han obtenido el reconocimiento formal de la mayoría de los territorios que habitan, en algunos casos logrando la escrituración de las propiedades familiares, y en otros, mediante su inscripción como comunidades indígenas. 
MOCASE-VC y los significados alternativos que ofrece la organización colectiva. Parto de la hipótesis de que las mujeres organizadas en el MOCASE - Vía Campesina son sujetas políticamente activas, que hacen uso creativo de distintas opciones disponibles dentro de un margen estrecho de opciones y de múltiples condicionamientos. En este punto, intento correrme de ciertos sesgos permeados en los análisis feministas que sitúan a las mujeres de contextos periféricos al denominado Primer Mundo preponderantemente como víctimas más que como agentes de su propia historia, sin apreciar el valor de sus resistencias, luchas y reflexiones (Curiel, 2007). Por otra parte, también analizo los condicionantes materiales y socioculturales, incluyendo de manera central las relaciones de género que condicionan a las mujeres del MOCASE-VC en su sexualidad, reproducción y usos del tiempo, visibilizando las desigualdades y dificultades que afrontan.

La relevancia que tienen las mujeres organizadas en el MOCASE-VC es que puede dar cuenta de un recorrido complejo (muchas de ellas han comenzado a participar de la política comunitaria junto a sus familias desde la infancia) de reflexión y de políticas que han incluido y atendido los asuntos de familia y de género, que busca defender su identidad y autonomía, pero asimismo enriquecerse de otros discursos. De este modo, como venimos argumentando en trabajos previos, las mujeres del MOCASE-VC buscan una voz feminista «propia». No se trata de mujeres que simplemente aceptan y defienden tradiciones. Tampoco desean dejar de ser campesinas - una identidad sobre la cual se afirman con orgullo - para parecerse a «otras». Estas definiciones afectan sus maneras de pensar la maternidad y dan cuenta de que no existen solo dos caminos: el del atraso y el de la modernidad. Es así que este trabajo es recorrido por la pregunta: ¿cómo es ser madre en el MOCASE-VC? ¿Qué sentidos, costes y satisfacciones tiene, según las mujeres campesinas organizadas?

\section{ASPECTOS METODOLÓGICOS}

Como adelantamos, este artículo se ha organizado a partir de un nodo temático específico (la problemática de las maternidades y la crianza en el MOCASE-VC) que se integra en una investigación etnográfica de mayor alcance, iniciada en 2015 y aún en curso.

El análisis aquí se centra en mi experiencia de campo con mujeres que participan desde una de las diez centrales campesinas en las cuales se organiza el MOCASE-VC y tienen una extensa trayectoria (entre diez y veinte años) de militancia política en el MOCASE, manteniendo su modo de vida campesino en 
sus hogares ubicados en alguna de las comunidades de base, pero frecuentando con periodicidad otros entornos mediante viajes, participación en actividades y eventos de organizaciones campesinas y urbanas, asistiendo a capacitaciones políticas, etc. Esto les permite traspasar las fronteras de su propio grupo.

Tomando como punto de partida el enfoque etnográfico (Aschieri y Puglisi, 2010; Guber, 2011) y considerando que la mayoría de integrantes del MOCASE$\mathrm{VC}$ vive en zonas rurales socioeconómicamente marginadas y de difícil acceso, se ha diseñado un plan de trabajo basado principalmente en «estancias convivenciales periódicas» (semanales) en diferentes hogares campesinos. Las dificultades para conseguir alojamiento próximo a los parajes rurales son conocidas por las familias campesinas, que acostumbran recibir visitas de otras organizaciones afines ${ }^{4} \mathrm{y}$ amablemente ofrecen sus hogares.

Estos inconvenientes se han convertido en ventajas de cara a los intereses etnográficos, especialmente dada mi preocupación por los aspectos políticos que se dirimen en la vida cotidiana, y en cuanto a la redistribución de roles y tareas también al interior de los hogares. Por su parte, las mujeres y varones militantes valoran el conocimiento construido en el campo, apreciando que en este caso la investigadora conozca de hecho su modo de vida y los acompañe en su rutina y vida social cotidiana. Esto refuerza los lazos de confianza construidos entre ambas partes y fortalece las posibilidades de conocimiento.

De este modo, para la investigación general se llevó a cabo un plan de visitas entre 2016 y 2017 (con expectativas de continuidad), estableciendo lazos con varias familias campesinas a través de otros miembros incorporados a la organización en calidad de técnicos ${ }^{5}$ que residen en Buenos Aires o que tienen la posibilidad de mantener contactos y correspondencias virtuales.

Este trabajo se ha basado en ciertas líneas emergentes que recuperan hallazgos previos, pero focaliza en las entrevistas y observaciones recabadas en mi última visita al campo, durante el segundo trimestre de 2017, a la central campesina de Quimilí y a la comunidad de base denominada Santa Rosa. Este paraje se conforma de unos dieciocho hogares familiares — distanciados entre sí por 1 a $5 \mathrm{~km}$ 一, de los cuales catorce forman parte de la organización. A su vez, esta experiencia se suma a dos anteriores realizadas durante 2016 en la comunidad de Rincón de Saladillo, perteneciente a la misma central campesina.

En general aquellas que integran la Vía Campesina.

Se denomina así en la organización a los y las militantes no campesinos, provenientes de otras organizaciones urbanas que se han mudado e integrado al MOCASE-VC. 
Además de la observación participante durante todas las instancias de nuestra estancia convivencial (reuniones familiares, participación en las tareas hogareñas como preparación de los alimentos, mateadas, pastoreo de los animales, momentos de esparcimiento y juego con los niños y niñas, etc.), se han creado algunos dispositivos específicos que consisten básicamente en entrevistas grupales semidirigidas a mujeres y varones que son militantes históricos ${ }^{6}$, y entrevistas en profundidad (Hammersley y Atkinson, 1994; Oxman, 1998) dirigidas únicamente a mujeres con el criterio de selección de que sean madres, militantes históricas y residentes de la comunidad. Las edades son variables (entre 16 y 57 años), ya que no se realizó la selección según edad y estado civil. Del total, cuatro de ellas eran casadas (esto se corresponde a la pauta cultural mayoritaria), mientras que la más joven era madre soltera y convivía con sus hermanos más pequeños y su madre, quien también fue entrevistada.

Para la realización de entrevistas y observaciones participantes, se han integrado las técnicas de relatos de vida (Wacheaux, 1996; Pujadas, 2000) y los aportes epistemológicos feministas (Reinharz y Davidman, 1992; Fonow y Cook, 2005), que han contribuido especialmente a la construcción interpretativa de los sentidos asignados a la maternidad y a la crianza desde la perspectiva de las mujeres campesinas.

Como última reflexión metodológica, dado que el MOCASE-VC se extiende a lo largo de toda la provincia de Santiago del Estero - y también a provincias fronterizas de gran superficie-, las variaciones geográficas, de pertenencia étnica de las comunidades, antigüedad de la organización política comunitaria, etc., dan cuenta de una enorme heterogeneidad. A esto se agrega que las mujeres que son militantes políticas por lo general llevan ya varios años de experiencia, algunas más dedicadas a la articulación con otras organizaciones rurales y urbanas de nivel nacional y también internacional ${ }^{7}$, y otras más al interior de sus comunidades.

Estas circunstancias, sumadas a las diferentes distancias y dificultades en la comunicación con los centros urbanos, las distintas edades de las mujeres entrevistadas, etc., presentan un panorama amplio respecto de la maternidad y una

6 Término de la propia organización para hacer referencia a los referentes políticos con participación activa desde sus orígenes o, desde hace ya muchos años, con gran presencia en la organización, ya que su estructura horizontal no permite hablar de «líderes» debido a que no cuentan con cargos o categorías diferenciales.

7 Las organizaciones regionales con las que se contactan más asiduamente son el MST de Brasil, el Movimiento Zapatista de México y las organizaciones de mujeres ANAMURI y CONAMURI de Paraguay y Chile. 
cantidad de discursos y conocimientos más tradicionales y otros más novedosos que circulan, se intercambian y se dirimen entre ellas y también con sus compañeros varones. Todo ello torna difícil suponer que las mujeres militantes del MOCASE-VC desconocen que la maternidad, la crianza y los usos del tiempo presentan diversidad entre distintos sectores sociales y que son asuntos políticos sobre los cuales se disputan sentidos e intereses.

En este sentido, prefiero hablar de maternidades y crianzas en el MOCASE$\mathrm{VC}$, en plural, y tomar esta heterogeneidad como un dato a destacar, con fines de problematizar la noción del sentido común en torno a la supuesta uniformidad $\mathrm{y}$, por lo tanto, el desinterés investigativo sobre la maternidad de las mujeres campesinas organizadas.

\section{LAS MATERNIDADES DE LAS MUJERES CAMPESINAS: ¿QUÉ DESAFÍOS PLANTEAN A LOS DEBATES FEMINISTAS?}

Ya han transcurrido varias décadas de estudios feministas históricos, antropológicos y desde varias disciplinas, que han cuestionado el postulado de que la maternidad consiste en el amor y la dedicación al niño o niña que brota naturalmente desde una supuesta esencia femenina (Badinter, 1991). Esta línea de investigaciones ha analizado con sentido crítico las transformaciones que han sufrido las formas de crianza y los sentimientos asociados a la gestación y a la procreación biológica, así como ha señalado la creación de normas y mandatos culturales y la estigmatización a las mujeres que se desvían de ellos (Nari, 2000; Di Liscia, 2005).

En el occidente contemporáneo, se ha creado el modelo que Hays (1998) denominó como «maternidad intensiva», el cual asume que la crianza «debería estar centrada en las necesidades de los niños, con métodos que estén determinados por expertos, así como implicar una atención intensiva y ser costosa» (p. 48). Esta noción de que las buenas madres son aquellas capaces de proveer cuidados y atenciones suficientes a sus hijos e hijas coloca del lado de la inadecuación a las mujeres que se alejan de dichos estándares, tanto si son evaluadas desde el plano psicológico como debido a variables socioculturales. Las imágenes estereotipadas de la buena madre, considerada como tal a aquella que acuña los valores y pautas de cuidado de los sectores medios urbanos occidentales, y la oposición con la mala madre para aquellas incapaces o desviadas de los patrones establecidos, también han sido problematizadas por distintas autoras (Knibiehler, 1997).

Palomar Verea (2004) ha descrito cómo, en torno a la maternidad, ha sido creada una serie de «mandatos» que prescriben el correcto ejercicio de los cuidados. Estas 
prescripciones son «encarnadas» en distintos períodos por instituciones y sujetos claves que producen «un complejo imaginario maternal basado en una idea esencialista respecto de la práctica de la maternidad» (p. 16). Este ideario normativo parte del modo de vida de la modernidad occidental, especialmente de los sectores medios urbanos, que reúnen ciertas condiciones y posibilidades respecto de los usos del tiempo, el capital económico y social, la higiene, etc. Por otra parte, las mujeres que son madres en los sectores urbanos más relegados, o en áreas rurales/indígenas (en las cuales las pautas culturales diferentes se imbrican a su vez con la realidad de la marginación sociocultural) son construidas desde los discursos hegemónicos (sanitarios y gubernamentales) como aquellas más alejadas de dicho patrón.

Las mujeres campesinas con quienes hemos realizado nuestro trabajo han crecido y viven en contextos en los cuales tradicionalmente se valora positivamente a la familia extensa y, además, donde la mayor cantidad de hijos e hijas representa una manera de asegurar la cantidad de manos suficientes para sostener las tareas de la unidad doméstica. De esta forma se han pronunciado ellas mismas respecto de la cantidad de hijos promedio que existen hoy en cada hogar campesino, con expresiones tales como «en mi familia siempre hubo muchos chicos, a nosotros nos gusta». Pero al mismo tiempo, he podido observar la realidad de que los aprendizajes de las distintas tareas necesarias para la subsistencia se van incorporando en los niños y niñas paulatinamente desde muy pequeños (autora, notas de campo). De este modo, las mujeres campesinas que tienen demasiados hijos e hijas, no siempre producto de embarazos planificados, en condiciones y edades caracterizados como desfavorables, se alejarían de aquella imagen materna asociada a los ideales de preparación y responsabilidad por la salud y el bienestar del niño.

En este punto, nos encontramos, por una parte, con que la línea de los estudios feministas nos posibilita adentrarnos en este terreno de la vida social relegado de los estudios sociales y tradicionalmente considerado como ámbito privado, en oposición a las esferas públicas de interés social e investigativo, o donde ocurre lo político. Estas perspectivas han sido pioneras en incluir esta dimensión de la vida social como espacio en donde ocurren relaciones de poder, ocupándose de desmontar la imagen romantizada del hogar como refugio, historizando y politizando la vida privada y la familia (Rapp, 1982).

Por otra parte, ha habido ya varios señalamientos dentro del feminismo, principalmente desde estudios no europeos, en torno a la representación de las mujeres del Tercer Mundo como objeto y no como sujetos de su propia historia y experiencias particulares (Mohanty, 1985; Andalzúa, 2004). 
Partiendo de estas reflexiones, planteo mi cuestionamiento a la tendencia mayoritaria en los estudios sobre transformaciones en la maternidad (es decir, asumiendo la existencia de dinámicas novedosas) de emplazarse en contextos urbanos. Dichas investigaciones, que atestiguan la existencia de cambios en las formas de ser madre, suelen aludir a contextos y sectores sociales para quienes las nuevas tecnologías reproductivas, la subrogación de vientres y las adopciones formales, entre otras formas recientes, resultan alternativas posibles para (re) pensar las formas de construir la maternidad.

Sugiero que este sesgo implícitamente podría colaborar con el imaginario común que opone a las mujeres modernas (buenas madres) de las campesinas, condenadas a la tradición, en quienes no acontecería ningún tipo de cambio.

Por otra parte, para nuestro caso de estudio se agrega que, en muchas ocasiones, las mujeres tienen su primer embarazo durante la adolescencia. Con relación a este punto, hemos observado el señalamiento que realiza Adaszco (2005) en torno a los sentidos sobre maternidad en la adolescencia: la tendencia mayoritaria parte de la idea de que las adolescentes de sectores populares no tendrían la madurez psicológica ni la información necesaria para ponderar los costos de sus acciones. Sin embargo, más recientemente, los estudios se inclinan por atender también las valoraciones y efectos positivos que puede acarrear la maternidad en las vidas de las mujeres en dichas situaciones, y en las estructuras de desigualdad social que rodean dichas prácticas más que en la decisión de las mujeres en sí misma (Adaszco, 2005).

Como ha sido sugerido por Vázquez Laba y Páramo Bernal (2013) para las mujeres campesino- indígenas de la región norte de Argentina, tanto la maternidad como la familia extensa son factores que aumentan el estatus y la integración social en comunidades de estilo de vida rural y políticamente organizadas. Esta idea de que la maternidad en contextos de fuertes desigualdades de género y clase no solo emerge como «destino», sino como fuente de reconocimiento social, mayor autonomía y acceso a los recursos, también ha sido señalada en otros estudios (Aquino, 2003). No obstante, estos y otros trabajos no profundizan en cuanto a los costos que conlleva dicho reconocimiento comunitario ni en la maternidad como fuente de desigualdades al interior de las comunidades.

Retomando estas argumentaciones, para las mujeres con quienes hemos construido estos datos también es posible afirmar que ellas, en tanto mujeres con una extensa trayectoria militante, son conocedoras de que sobre sus cuerpos y decisiones se entrecruzan obstáculos y presiones múltiples, tanto desde sus pertenencias étnico-comunitarias como desde los discursos normativos con respecto al género. 
De esta manera, aquí indagamos en torno a los condicionantes, pero también sobre los sentidos y respuestas de las mujeres campesinas organizadas en el MOCASE-VC: ¿qué ocurre con sus formas de asumir la maternidad y la familia en contextos rurales? ¿Cuáles son las posibilidades que ofrece este modo de vida alternativo creado a partir de la acción colectiva? ¿Cuáles son sus limitaciones y qué costos tiene sobre sus cuerpos?

\section{¿SON HIJOS/AS DE TODOS/AS?: LO POLÍTICO, LO PRIVADO Y LAS CARGAS DE TAREAS SOBRE LAS MUJERES}

Los estudios que han abordado la cuestión de la construcción identitaria del MOCASE-VC ya han formulado con bastante consenso la idea de que el colectivo de campesinos y campesinas se nuclea en torno a la defensa del territorio con dos líneas claras de acción: por una parte, la confrontación y el reclamo al Estado, y por otro, la tarea interna de resistencia en el territorio y formación «hacia adentro» (Durand, 2006; Michi, 2010). Ya en su acta fundacional se destaca como «corazón del proyecto» la creación de «prácticas cotidianas que contengan en sí mismas la reproducción de una sociedad solidaria y rompan la lógica mercantil globalizada», con la noción de concientización como palabra clave (MOCASE VC, 2004). Tal como ha sido señalado por la línea de trabajo de Michi (2010) desde el interés por las prácticas educativas del movimiento social:

En la defensa efectiva del territorio se articula lo material (las posibilidades de subsistencia dadas por la conservación de la tierra y de una forma de producción y reproducción) y también lo simbólico (identidades, valores, discursos) [... Se trata de la disputa por una forma de vida que no puede reducirse a valores posmateriales, pero que, tampoco, es puramente económica [...]. Es una lucha económica y también moral (Michi, 2010, p. 229).

Esta construcción se va a anclar tanto en relación con el pasado como con el futuro, posicionándose entre continuidades y rupturas. De un lado, se reconoce la importancia de recuperar prácticas «antiguas» basadas en la solidaridad comunitaria y en la pertenencia indígena de muchos de sus habitantes, costumbres que se consideran perdidas por la lógica del individualismo capitalista (Michi, 2010). Del otro, la defensa del territorio se orienta hacia su propia resignificación: «queremos la tierra, pero ¿para qué vamos a usarla?», rememoraba una militante histórica sobre los interrogantes que guiaban las reuniones en etapas iniciales. Esta redefinición va a recrear un modo de vida campesino fundado en vínculos 
solidarios y horizontales, y una sociedad nueva que incluye en su horizonte la redefinición de los roles de género y la apropiación de nuevos conocimientos. Vida campesina, territorio y comunidad van a ser los ejes centrales en derredor de los cuales se van a organizar distintos tipos de prácticas y objetivos.

En este marco de significados, los niños, niñas y jóvenes van a cobrar un valor fundamental: son ellos y ellas la esperanza en las nuevas generaciones, la continuidad de la idea original y la posibilidad de un cambio a futuro. También representan la permanencia y herencia de los territorios, y se busca evitar la tendencia a las migraciones y al trabajo asalariado informal, experimentados como destinos forzados $^{8}$. Con relación a la crianza y a los cuidados de los más pequeños, ha sido recurrente durante mi trabajo de campo la expresión: «acá son hijos de todos».

Dicha significación se imprime en la práctica principalmente debido a la necesidad de articular políticamente con otras organizaciones nacionales y regionales, y también con la asistencia a reuniones internas de la organización que se dan lugar en las centrales o van rotando entre los diferentes parajes. Debido a las dificultades y costes de transporte que sufren quienes viven en zonas distanciadas, anegadizas y de difícil acceso, se ha requerido la formación de varones y de mujeres, pero también de las comunidades de base en su conjunto, para estar dispuestos asumir tareas de cuidado cuando algún miembro de la familia está ausente durante varios días, o incluso, semanas.

En este sentido, el MOCASE-VC respeta una organización en gran media simétrica entre varones y mujeres, ya que la asignación de estas tareas es rotatoria y representa un compromiso obligatorio: «al que le toca le toca», han mencionado tanto mujeres como varonesorganizados, que no son muy adeptos a viajar y alejarse de sus entornos rurales. Así ha resultado durante mis visitas, en las cuales siempre mencionaban algún integrante de las distintas familias que estaba de viaje o de recorrida por otros parajes o centrales campesinas. En la misma línea, al compartir instancias con el grupo de técnicos, varones y mujeres, han reiterado la noción de que «son hijos de todos». Durante una de las semanas que coincidía con mi trabajo de campo, uno de los seis grupos familiares que se han mudado a zonas

8 Es así que, desde 2001, el movimiento lleva a cabo los Campamentos Latinoamericanos de Jóvenes (convocando a otras organizaciones campesinas y urbanas) al tiempo que ocupa gran parte de su central campesina original para el desarrollo de la Escuela de Agroecología (de nivel medio), que actualmente se ha desarrollado y a la que llegan jóvenes campesinos de otras regiones del país. Más recientemente también ha sido creada la primera Universidad Campesina (UNICAMP) de la Argentina, destinada a la formación de las nuevas generaciones en cuestiones políticas, ideológicas, y también relativas a la producción agropecuaria. 
aledañas a la central campesina Quimilí para dedicarse al trabajo político junto a la organización se hallaba a cargo de los niños y niñas de otras tres parejas adultas que estaban dedicadas a la enseñanza universitaria en la Universidad Campesina (ubicada en una localidad alejada).

Estos y otros dispositivos marcan una intencionalidad y un consenso con relación a que los asuntos de los niños, niñas y jóvenes incumben a todo el movimiento, que muchas veces interviene en cuestiones del ámbito familiar en lo que hemos denominado ya en otro artículo como la «borrosidad de fronteras entre lo público y lo privado» (Pena, 2017a).

Sin embargo, ¿cómo se practican estos significados políticos en la cotidianidad de los parajes campesinos y qué efectos novedosos y costes tiene en las mujeres organizadas?

Durante mis estancias convivenciales en los dos parajes rurales que he visitado, he podido observar que muchos de los hogares aún conservan un patrón de vida campesino centrado en el autoabastecimiento, combinado con pequeños ingresos monetarios provenientes de subsidios estatales e internacionales y de trabajos temporarios informales. Sin embargo, la mayor parte del tiempo, tanto de mujeres como de varones, se reparte entre tareas de producción tales como el sembrado, cosecha y pastoreo de animales, tareas de mantenimiento y refacción de las unidades domésticas, la crianza de niños y niñas y las actividades relativas a la participación política en el movimiento.

En primer lugar, si bien el ideal de «crianza comunitaria» funciona como utopía y como valoración y promoción de las relaciones de solidaridad, debido a la disposición de los hogares (entre 1 a $5 \mathrm{~km}$ entre ellos) y las pautas de vida tradicionales no consiguen modificar el patrón de crianza centrada en los hogares familiares (compuestos en su mayoría por la familia extensa). Desde la utilización del territorio, lo comunitario es defendido y practicado principalmente mediante el mantenimiento el uso comunitario del monte, lo que implica que no existan alambrados en espacios utilizados por las familias vecinas para el pastoreo del ganado, la caza, la recolección de hierbas y vegetales, el paso, etc., sin delimitaciones. Este modo de sociabilidad y uso del territorio, que es activamente promovido, también puede facilitar el estrechamiento de los lazos de vecindad y proximidad afectiva (los niños, niñas y adolescentes pasan más tiempo juntos, se visitan con frecuencia y los adultos los conocen y los cuidan).

No obstante, me atrevo a sostener que alivian, pero no erradican la sobrecarga de tareas que recae en las mujeres. Desde el testimonio de campesinos y campesinas, se destaca que antes de la organización primaba un patrón de 
distribución de tareas según los sexos marcadamente tradicional (cerrado sobre la familia nuclear o extendida) y asimétrico. Las mujeres que se casaban no solo se ocupaban de las tareas domésticas (preparación de los alimentos, higiene de los niños y niñas, limpieza del hogar, etc.), sino que sus tareas en la producción de alimentos eran invisibilizadas. Además, se sostenía una actitud de servilismo, subordinación e infantilización frente a sus maridos, a quienes debían pedir «permiso» respecto del uso de sus tiempos y recursos y eran «regañadas» por ellos de manera legitimada (Pena, 2017a).

Como parte de la trayectoria formativa del movimiento, en un inicio debido a la necesidad de fomentar la participación política de las mujeres, se fomenta y se crean valores alternativos basados en la igualdad de roles y tareas según los sexos, tanto al interior de los hogares como en los espacios públicos. De allí, no es de sorprender que, ante la presencia de la investigadora en los hogares, tanto mujeres como varones se esforzaban y enorgullecían de mostrar la participación activa de los compañeros varones en tareas de crianza y de hogar, tales como el aseo y la preparación de los alimentos. A menudo comparaban los tiempos «antiguos» (o sus memorias de la infancia, en el caso de personas de mediana edad) en contraste con la democratización que han logrado a partir de los talleres formativos y la experiencia política. Hoy en día se valora el desempeño de las mujeres en otras áreas, así como se fomenta la redistribución equitativa de tareas domésticas entre varones y mujeres.

Actualmente, la mayoría de los hogares campesinos que hemos conocido se hallan conformados por al menos tres generaciones, incluyendo a uno o más adultos mayores, a una cantidad variable de entre cinco a diez niños y niñas y en algunos casos hijos e hijas pequeños de hijas mujeres solteras. De este modo, también, los niños y niñas mayores y adolescentes tienen una participación gradual y responsabilidades crecientes en todas las tareas, incluyendo tanto el cuidado de sus hermanos más pequeños como el de los animales, lo que resulta clave en el desempeño cotidiano de toda la familia.

Por otra parte, tampoco resulta fácil distinguir el límite y la cantidad de tiempo dedicado a las tareas domésticas respecto de las que consideran como productivas. Un día típico en las comunidades de base del MOCASE-VC comienza con la preparación del fuego para el desayuno, el aseo de los hogares y de los niños y niñas (la mayoría van solos a las escuelas del paraje durante un turno de cuatro horas diarias) y un transcurrir del tiempo intercalado entre el cuidado de los animales (que se encuentran rodeando las casas campesinas), el acarreo de agua u otros recursos), las actividades de sembrado, la preparación de alimentos, 
algo de tiempo para el ocio (mateadas, conversaciones con los vecinos, tiempo de siesta, etc.) y más tiempo durante la tarde noche dedicado al aseo, las tareas escolares y, nuevamente, la preparación de alimentos. Nada resulta sencillo en parajes caracterizados por la ausencia de recursos básicos tales como el gas, en ciertos casos la electricidad, y la cercanía a los pozos de agua. Estas cuestiones, sumadas a las características adversas de los suelos y del clima, hacen que incluso las tareas más pequeñas demoren y cuesten más esfuerzo de lo imaginado.

Los discursos de las y los militantes del MOCASE-VC insisten en que «acá todos hacemos de todo», lo cual, en comparación con los patrones tradicionales resulta en gran medida cierto. No obstante, hemos tenido oportunidad de observar y de participar en rutinas diarias que repiten día a día la distribución de algunas tareas marcadamente según el sexo. Por una parte, solo los varones se encargan de las tareas de caza de pequeños animales (subsidiarios e insuficientes para la alimentación), en la cual suelen participar los adultos junto a las jóvenes generaciones, que van aprendiendo las distintas técnicas desde pequeños. Por otro, si bien en la preparación de los alimentos y en el cuidado y aseo de los niños pequeños participa «toda la familia», prevalece la feminización de las tareas, y especialmente la «responsabilidad» asignada a las madres y a las hermanas mujeres mayores. Desde nuestro punto de vista, esto no es un dato sorprendente ni propio del MOCASE-VC si tenemos en cuenta que esa es la distribución social normativizada y predominante en la gran mayoría de los sectores sociales, de la cual los campesinos y campesinas organizados, si bien procuran construir sentidos alternativos, no están exentos.

Lo que por cierto seguramente escasea para todos, pero en mayor medida para las mujeres campesinas, es el tiempo para la soledad. El tiempo pasado en solitario o «sin hacer nada» es moralmente condenado, e incluso para las mujeres que entrevistamos resulta impensable, si bien son frecuentes las expresiones de agotamiento. El clásico libro de Murillo (1996), ya hace más de dos décadas, se ha ocupado de analizar de qué modo, desde la perspectiva de las mujeres, el tiempo libre es en realidad un tiempo y un lugar que nos ha sido tradicionalmente asignado como de cuidado y atención a otros, en especial al interior de la familia, privando a las mujeres del ocio y del tiempo para sí mismas. Esto es más cierto para las mujeres del MOCASE-VC, no solo para las que son madres desde niñas o adolescentes sino hasta para las que son abuelas y bisabuelas. El tiempo dedicado a los cuidados y a la familia, así como a los animales y otras tareas consideradas productivas, nunca acaba: desde que amanecen hasta que se duermen. Esto ha sido observado por mí y también reconocido por ellas: 
Yo me levanto seis y media de la mañana porque los chicos entran a las ocho de la mañana y es oscuro todavía. Me levanto a hacer el fuego, poner el agua que se caliente, hasta que ellos se levanten y de ahí ya se empieza... la idas y venidas de la casa, tenés que barrer, tenés que ir después al corral, tenés que ver los chanchos... así hasta que me acuesto. En el campo no se termina de trabajar nunca (Marisa, militante histórica, central de Quimilí).

La noción de que todo es trabajo es un logro de la formación pedagógica realizada por el movimiento. Como suelen señalar las mujeres: «Antes, cuando nos preguntaban si trabajábamos, decíamos que no, porque no sabíamos; después nos dimos cuenta de que trabajamos sin parar todo el día». Sin embargo, la imposibilidad de transformar completamente este tipo de prácticas resulta sin dudas en una gran fuente de angustia y opresión que no han sido totalmente capaces de verbalizar, o al menos no ha emergido de forma clara durante el tiempo de nuestra investigación. Esto no se debe únicamente a la repetición de pautas patriarcales sino a su interseccionalidad con otros condicionantes, principalmente materiales: es decir las condiciones de pobreza y marginalidad, algo que no debería de ningún modo perderse de vista en este análisis. La mayoría de los hogares son muy pequeños, y cuando algunas de las familias consiguen reunir un pequeño ingreso monetario, construyen con sus propias manos hogares para los nuevos matrimonios y sus hijos e hijas, pero por lo general lindando con las casas de los mayores debido a pautas culturales $\mathrm{y}$, fundamentalmente, a la necesidad de «sumar manos», en sus palabras, para las distintas tareas campesinas.

Dicho esto, no es tampoco posible o fácil distinguir las fuentes de cansancio y los costes emocionales y físicos provocados por este modo de vida de las fuentes de satisfacción. Y aquí retomo circularmente mi interrogante sobre los sentidos de la maternidad en las mujeres campesinas del MOCASE-VC.

Muchas de las mujeres organizadas han tenido experiencias previas (a los tiempos de la organización) de migración económicamente forzada a los centros urbanos, principalmente como empleadas domésticas. En sus relatos, la posibilidad de volver al campo, de resistir en sus territorios originarios y de «vivir rodeada de animales y de niños y niñas» también aparece como un fuerte sentido de libertad y dignidad: «aquí no tenemos jefes»; «hacemos lo que queremos cuando queremos» $\mathrm{o}$ «hago las cosas cuando no estoy cansada» son manifestaciones frecuentes.

En contraste con nuestras observaciones, podría decirse que dichas expresiones hablan más de la identidad ideal construida que de la realidad que viven todos los días. Por otro lado, también, creo, hay algo de cierto en sus voces. He 
tenido oportunidad de comprobar la angustia y ansiedad que sienten cuando están fuera de sus comunidades, donde me ha resultado muy difícil conversar con ellas distendidamente; en contraste al tiempo, comodidad y amabilidad que han tenido posibilidad de brindar estando en sus hogares. Es recurrente la frase de que en el pueblo o en la ciudad «extrañan a sus niños, animales y plantas».

Mi argumento se vincula con el hecho de que es este y no otro el modo de vida que debe ser tenido en cuenta a la hora de investigar, analizar y también de implementar políticas públicas referidas a la planificación familiar y a la maternidad en las mujeres campesinas organizadas.

En este marco, tanto la prevención de embarazos como la maternidad no se viven de igual manera en adolescentes solteras como en mujeres casadas y pertenecientes a un grupo familiar conformado por ellas y sus parejas, así como no todas ellas lo viven por igual. Tampoco es vivenciado de la misma manera que en los entornos urbanos medios -implícitamente tomados como norma, me atrevo a sugerir-, donde cada nuevo niño o niña implica una reorganización de tiempos, energías y aspiraciones que resultan ajenos para las mujeres campesinas. En el campo, un nuevo integrante de la familia muchas veces no representa un coste de energía tan grande como para la familia nuclear urbana, ya que los más jóvenes son cuidados en gran medida por sus hermanos y hermanas mayores y, asimismo, implican una ayuda, acompañamiento y fuente de alegría en las tareas diarias.

A esto debe agregarse, fundamentalmente, que para quienes la participación política en el MOCASE-VC representa en gran medida una forma de identidad, la posibilidad de permanecer en el territorio junto a sus hijos e hijas es también una práctica de resistencia dignificante y fortalecedora.

De esta manera, para las mujeres militantes del MOCASE-VC mantener el estilo de vida centrado en el grupo familiar y ser madres de muchos hijos también es una manera de reivindicar la identidad y los sentidos que están en juego en la lucha política más amplia, y una forma materialmente viable de llevar acabo el autosustento de los hogares. Esto no significa que se encuentren por completo subsumidas a la tradición y que desconozcan las desigualdades que acarren estas prácticas. Por eso participan políticamente: para defender sus intereses y para construir relaciones más simétricas entre las parejas casadas y entre adultos, niños y niñas (Pena, 2017b). Así, estos hallazgos y reflexiones indican que en el campo existen dinámicas novedosas, transformaciones respecto de las prácticas de crianza y maternidad y disputas llevadas a cabo por las mujeres campesinas que no necesariamente tienen que ver con postergar o reducir la cantidad de hijos e hijas (al menos no única ni necesariamente), sino con redistribuir el peso de las 
tareas que recaen en ellas y conseguir mejoras en la calidad de vida, severamente dañada. La maternidad tiene en el medio rural que hemos estudiado otros sentidos y formas de practicarla, sin pretender relativizar las dificultades y opresiones patriarcales y materiales que sufren las mujeres campesinas.

\section{CONDICIONAMIENTOS, TRADICIONES Y DESEOS EN PLANIFICACIÓN DE LA MATERNIDAD: «SÍ, AQUÍ EN EL CAMPO TENEMOS MÁS HIJOS QUE USTEDES»}

Mis amigas, que son de la edad mía, 33 años, la mayoría tiene cinco o seis hijos. Ojo que a mí también me encanta tener hijos, si no hubiese tenido el problema de fibroma hubiese tenido muchos hijos, porque también está eso... Mis amigas, la mayoría tiene cinco o seis hijos, y no los tienen seguiditos, los tienen con tres o cuatro años de diferencia [...] y en general me dicen «lo estábamos buscando». Pero las más chicas por lo general no, te dicen «se dio y ya está». Y otras compañeras decían también en las capacitaciones, que para ellas es así, si viene, viene, no les preocupaba tanto (Silvina, militante histórica, central de Quimilí) $)^{9}$.

En el caso de Silvina, la mujer que citamos arriba, participa del MOCASE-VC desde los doce años, porque acompañaba a su padre y a su madre, pero también debido a sus motivaciones personales de formar parte de actividades comunitarias tales como la radio del movimiento, reuniones y asambleas. Como hemos argumentado en otro trabajo, para muchas mujeres campesinas los inicios de la organización representaron en el ámbito individual más que una lucha por la tierra (un problema que no aquejaba con la misma urgencia a todas las comunidades) una manera de traspasar las fronteras de la unidad doméstica y la familia para formar parte de la vida comunitaria y política, que les resultaba atractiva desde jóvenes (Pena, 2017a).

Esta trayectoria marca en Silvina, como ejemplo de la mayoría de las mujeres a quienes hemos entrevistado, una biografía caracterizada por cambios a partir de la posibilidad de integrar espacios de intercambio social y político. En el MOCASE-VC, la participación implica de manera enfática la preocupación por la instancia reflexiva y pedagógica en cuestiones relativas a la identidad, la importancia de la vida política y los horizontes comunes a construir en tanto

9 Los nombres propios han sido modificados para preservar el anonimato de las informantes, mientras que se ha respetado con su consentimiento el lugar de procedencia. 
movimiento social. A partir de su extensa experiencia con el uso de la palabra en dispositivos políticos reflexivos, tales como talleres y capacitaciones, las mujeres dan cuenta de una amplia capacidad para objetivar procesos y narrar sus propias vivencias, contradicciones y aspiraciones de manera crítica.

Por otra parte, sus vidas no dejan de estar marcadas por la falta de recursos materiales y culturales que deberían estar garantizados a lo largo de todo el territorio nacional, la marginación socioterritorial, la dificultad de comunicación con los centros urbanos y la discriminación que sufren con relación a su modo de vida rural.

Estos diacríticos condicionan fuertemente su acceso a la salud en general y el disfrute de sus derechos sexuales y reproductivos, incluyendo la (no) planificación familiar.

Por ejemplo, si bien los métodos anticonceptivos orales, inyectables y profilácticos se distribuyen en las salas de sus comunidades de base (aquellas que poseen una) o en los parajes o pueblos más cercanos, su obtención representa un costo de tiempo, de traslado y de contacto casi obligado con el personal médico (ante el cual suelen ofrecer resistencias, ya que muchas han sido víctimas de malos tratos), cuya responsabilidad recae en las mujeres. Tal como han señalado Vázquez Laba y Páramo Bernal (2013) para la región del noroeste argentino, las mujeres campesinas, indígenas y migrantes de sectores populares son subalternizadas, discriminadas y expulsadas de los servicios de salud, limitando su acceso a la información sobre los procesos de salud-enfermedad en general, así como a los de salud reproductiva en particular, y afectando su bienestar en general. Esto se debe, según las autoras, no principalmente a la falta de recursos específicos sino a «las resistencias dentro del sistema sanitario por parte de los profesionales de la salud, a partir de modelos ideológicos referidos a la maternidad, sexualidad y género que reactualizan prejuicios de clase y refuerzan relaciones de poder médico-paciente» (p. 8).

La argumentación aquí se vincula con el hecho de que la actuación de las mujeres militantes del MOCASE-VC demuestra mayor complejidad que el supuesto de que la mayor cantidad de embarazos se relaciona con el desconocimiento o falta de disponibilidad de métodos anticonceptivos o la repetición de pautas tradicionales. Las mujeres campesinas del MOCASE- VC son conocedoras y también articulan respuestas frente a las restricciones que sufren respecto de la implementación de los derechos y beneficios que deberían estar garantizados desde el Programa Nacional de Salud Sexual y Procreación Responsable y otras políticas públicas. 
Muchas veces, incluso al interior de la organización, se repiten nociones preconcebidas en torno a las mujeres que tienen mayor acceso a los contextos urbanos y las que viven más rodeadas del entorno rural de sus comunidades y «alejadas de las posibilidades». Una de las militantes del MOCASE que participa de la administración desde el centro urbano más cercano me ha comentado: « $\mathrm{Si}$ yo no hubiese tenido esta posibilidad, me hubiera quedado en el campo y hubiera tenido nueve o diez hijos», con el tono de quien logra escapar de un destino indeseado. El hecho de no utilizar métodos anticonceptivos para prevenir embarazos también ha aparecido desde las voces de otras mujeres campesinas más cercanas y conocedoras de los servicios de salud con énfasis crítico: «En general las mujeres los conocen, pero en el momento no les importa tanto» o «son cómodas».

Sin embargo, desde nuestra perspectiva estas prácticas abren el interrogante acerca de si existe un tipo de normatividad en torno a la planificación familiar y los cuidados también parte de un marco de sentido homogeneizante que no consigue contener a las mujeres campesinas y del cual ellas mismas se distancian. Aquí sostengo que la vida política ha afectado a todas las mujeres militantes, incluso a aquellas que viven en el campo, y que a partir de ello agencian un posicionamiento activo con relación a cuestiones de la vida privada tales como la maternidad, incluso afrontando múltiples adversidades que dejan sus posibilidades reducidas.

Del trabajo de campo realizado, durante conversaciones informales especialmente, emerge la utilización de métodos anticonceptivos de manera selectiva, e incluso estrategias de resistencia tales como el ocultamiento a la pareja, lo que sugiere la presencia de tradiciones patriarcales que pesan sobre los cuerpos de las mujeres bajo la imposición del rol maternal como destino. Pero también nos interesa indagar sobre el modo en que estas cuestiones - ya sabidas - se imbrican en el contexto estudiado con los significados positivos que las mujeres otorgan a la maternidad y con el modo en que las prácticas de crianza se desarrollan en un marco de vida comunitaria que asumimos como dinámica y en la que las mujeres, activamente, disputan roles, espacios de poder y posibilidades.

Sin subestimar las relaciones de poder que pesan sobre sus cuerpos, mi propuesta apunta a revalorar en el debate las respuestas que tienen ellas, reposicionándolas como sujetas activas. En el contexto estudiado, la maternidad, en determinados casos, también cobra para las mujeres campesinas el sentido de posibilitar la continuidad de un modo de vida que está siendo amenazado y de defender la dignidad de su identidad campesina. De este modo, muchas veces es elegida, pero también peleada, disputada, y modificada en sus modos de practicarla. 


\section{«DE ESO TODAVÍA NO SE HA HABLADO»: CUANDO LA MATERNIDAD NO ES ELEGIDA POR LAS MUJERES CAMPESINAS}

En comparación con el trabajo de concientización y de construcción de sentidos alternativos en torno a la redistribución de roles que ha realizado el MOCASE$\mathrm{VC}$ durante su trayectoria política, los temas de salud sexual y (no) reproductiva se encuentran entre los puntos más débiles o aquellos que encuentran mayores resistencias y temores a la hora de ser discutidos. Esta observación también es reconocida por las mujeres militantes de las distintas comunidades de base, tal como se manifiesta en el siguiente fragmento de entrevista grupal realizada a varias mujeres encargadas del trabajo político en el área de salud de la organización campesina:

E1: [Sobre los embarazos no deseados] No se ha hablado, pero nosotros... yo, en un principio había notado que había cambiado, pero si me dices hoy por hoy, yo que he andado hace poco ahora en el hospital, se ven de nuevo muchas chicas adolescentes embarazadas.

E2: Jovencitas, de quince, dieciséis años se ven.

Investigadora: ¿Sí?

E1: Sí, se ven, se sigue viendo esa cantidad de embarazadas.

M: ¿Creen que las jóvenes eligen cuando tener hijos o a veces no?

E1: Más que no, pero en definitiva lo toman igual. Pero no sé si a gusto, si lo han elegido.

Investigadora: ¿Y les gustaría trabajar ${ }^{10}$ más sobre eso?

E3: Sí, a mí me gustaría que se dé más lugar, me gustaría llegar a las charlas esas en cada comunidad, o en cada barrio, llegar a las charlas esas y desde mi experiencia ir viendo eso.

E1: Habíamos puesto como propuesta la vez pasada el hacer talleres en las comunidades y justamente para ir fortaleciendo esas cosas, pero no hemos empezado todavía.

Investigadora: ¿Es como que todavía está en un proceso?

E2: Sí, eso, hemos propuesto ya en lo último, de empezar a hacer talleres de salud, pero en vez de estar hoy aquí [en la central] estar en una comunidad y llevar folletitos, esas cosas.

E3: Ahora también eso se ha implementado en los colegios, las escuelas rurales que tampoco se hacía y ahora está. Ahora está en el colegio, en las escuelas, se habla mucho de eso.

10 Se refiere al trabajo político de base de la organización. 
En el mismo sentido, cuando realizamos observaciones participantes durante el transcurso de una de las jornadas del Taller de Sexualidad, destinado a las y los jóvenes que asisten a la Escuela de Agroecología —organizados y coordinados tanto por mujeres como por varones miembros del MOCASE-VC - han surgido muy escasas representaciones por fuera de la estrategia de «educación sexual» tradicional impartida en las escuelas públicas hace ya algunas décadas. Fundamentalmente, el taller se ha basado en las características anatómicas de los sexos y en los riesgos de las enfermedades de transmisión sexual (ETC), con muchos pudores y falta de información adecuada o de paradigmas más novedosos a la hora de verbalizar y debatir otras cuestiones.

Tanto las mujeres como los varones integrantes del MOCASE-VC asumen la importancia de que la formación abarque cuestiones de género y sexualidad, pero como ocurre en otras organizaciones mixtas, resulta el asunto más espinoso y difícil de tratar. A pesar de su reconocimiento, se evidencia todavía la necesidad de prácticas y discursos transformadores y de herramientas para ello, pese a sus contactos con otras organizaciones regionales de mujeres y a su proximidad con los técnicos provenientes de organizaciones urbanas. De acuerdo con mi experiencia de campo, ni estos intercambios ni la experiencia política propia han llegado aún a debatir asuntos que traigan a la luz problemáticas como el abuso sexual, las relaciones sexuales no consentidas o los embarazos no deseados. Claramente, se trata de los asuntos más complejos para un movimiento social que por el momento depende de la organización en forma de unidades familiares, un tema que ha sido ya observado por Paulilo (2009) para el caso del MST de Brasil.

En el abordaje académico del problema de las relaciones de género en movimientos sociales mixtos, ya se ha sugerido que, de manera frecuente, la presencia de las mujeres en espacios políticos resulta de por sí transformadora y que colabora en el cuestionamiento de las antiguas jerarquías basadas en el género. Dichas experiencias promueven en las mujeres la intencionalidad de revertir posiciones de subordinación. Si esto es cierto para el caso del MOCASE-VC, coincidimos asimismo con estudios como el de Paulilo (2009) y otros (Rubin, 1998; Da Silva, 2004; Furlin, 2013), que resaltan las contradicciones entre las propuestas y las posibilidades reales de concretarlas en la convivencia diaria de los campamentos o asentamientos de la organización, donde persisten muchas desigualdades.

En el movimiento campesino de Santiago del Estero también resulta dificultoso pensar en espacios destinados únicamente a las mujeres, tratándose de una organización social mixta que ha construido su identidad sobre la base del trabajo formativo conjunto de varones y mujeres y su base en la igualdad de roles 
y participación entre los sexos. Al preguntar sobre el tema durante las entrevistas, el mayor consenso (entre las mujeres) iba en la dirección de afirmaciones como la siguiente:

E: O sea, la mujer es la que se embaraza, pero en realidad responsables somos todos, digo. Si no hubiera un hombre, una mujer no se embarazaría, entonces tienen que tener conciencia los dos (Estela, militante histórica, central de Quimilí).

De esta manera, los temas de sexualidad e interrupción del embarazo resultan aún objeto de pudor, silencio y serias dificultades para poner públicamente en palabras y para concebir como temas políticos. Quedará pendiente para futuras investigaciones ahondar en torno a estas problemáticas, acuciantes de cara a los intereses y sufrimientos de las mujeres campesinas agrupadas en el MOCASE-VC.

A modo de cierre

Este trabajo aporta conocimiento en torno a la problemática de la diversidad que asumen las maternidades en la contemporaneidad, inscribiéndose en la línea de los debates feministas que han cuestionado su naturalización y han logrado visibilizar los costos del mandato maternal que pesa sobre las mujeres. La reflexión ha sido propiciada a partir de un contexto etnográfico que posibilita la observación de prácticas y sentidos en torno a la maternidad y a la crianza que pueden sugerirse como alternativos, tomando en consideración que forman parte de un entramado político de contestación a los valores del individualismo capitalista, y que asume como horizonte la creación de vínculos más simétricos y solidarios.

El movimiento campesino de Santiago del Estero-Vía Campesina ha construido su identidad en torno a los ejes de territorialidad, vida campesina, educación popular y soberanía alimentaria, proponiéndose la tarea de crear un nuevo modo de vida en todas las áreas de la vida social, incluyendo las relaciones familiares y entre los géneros. Hemos desarrollado la idea de que las prácticas vinculadas con la sexualidad, los cuidados, los usos del tiempo y la crianza de las nuevas generaciones deben ser comprendidas en este marco, partiendo del postulado feminista «lo personal es político». Las trayectorias biográficas de las mujeres militantes en la organización campesina se hallan íntegramente atravesadas a partir de la participación política. El estilo de vida que llevan a cabo no tendría lugar de no existir el movimiento social que permite la resistencia en el territorio, la creación de dispositivos comunales y la práctica política que en este contexto forma parte de la vida cotidiana, incluso como modo de sobrevivencia en enclaves aún vulnerables o amenazados por la disputa territorial. 
Dentro de esta coyuntura, hemos explorado las distintas realidades y conflictos que asume la maternidad, tomando la categoría de heterogeneidad en tanto dato que aporta al debate en torno a las transformaciones y continuidades en las formas de vivirla. A partir de este corrimiento, discutimos con la presunción frecuente de que en los entornos rurales y entre las mujeres de los sectores más marginados socioeconómicamente prevalecerían prácticas y sentidos ligados a la tradición. De este modo, han surgido al menos dos cuestiones significativas que vale la pena destacar.

Por una parte, sugerimos que la maternidad en el caso de las mujeres campesinas organizadas en el MOCASE-VC, lejos de encontrarse signada a la repetición de pautas tradicionales, se desenvuelve en tensión entre un conjunto de condicionantes económicos y culturales (abarcando por sobre todo la dimensión de género) y otros significados afirmativos posibilitados a partir de la práctica política. Para dichas mujeres, en tanto sujetas políticamente activas, la maternidad en algunos casos se resignifica como práctica de defensa de su modo de vida campesino, y forma parte de sus procesos subjetivos de construcción identitaria y de dignificación. A su vez, son conscientes de los costos y desigualdades que pesan sobre ellas y, por lo tanto, la transitan planteando resistencias y modificaciones vinculadas con la redistribución de las tareas domésticas y de crianza.

Por otro lado, hemos señalado las distancias entre los ideales construidos a modo identitario, sin duda significativos para el desenvolvimiento y la resistencia cotidianos, y las realidades que deben afrontar las mujeres diariamente. Si bien la sobrecarga de tareas para las mujeres y la feminización de los cuidados y de la crianza no han sido erradicadas, es un terreno sobre el cual la organización da cuenta de un recorrido político interesante y transformativo. Sin embargo, como mencionamos, las cuestiones relativas a la sexualidad, la planificación familiar y los embarazos no deseados aún son asuntos rodeados de pudor que resulta dificultoso asumir como políticos.

Será un gran desafío de cara al futuro para el movimiento de campesinos y campesinas, especialmente para las mujeres, incluir estos temas en sus debates formativos y en sus agendas políticas, así como dar mayor batalla sobre estas cuestiones en el plano de las prácticas cotidianas. 


\section{REFERENCIAS}

Adaszco, Ariel (2005). Perspectivas socio-antropológicas sobre la adolescencia, la juventud y el embarazo. En Mónica Gogna (org.), Embarazo y maternidad en la adolescencia. Estereotipos, evidencias y propuestas para políticas públicas (pp. 33-66). Buenos Aires: CEDES-UNICEF.

Andalzúa, Gloria (2004). Movimientos de rebeldía y culturas que traicionan. En Bell Hooks et al. (org.), Otras inapropiables. Traducción de María Serrano. Madrid: Traficantes de Sueños.

Aquino, Estela M. L., Maria Luiza Heilborn, Daniela Knauth, Michel Bozon, Maria da Conceição Almeida, Jenny Araújo y Greice Menezes (2003). Adolescência e reprodução no Brasil: a heterogeneidade dos perfis sociais. Cadernos de Saúde Pública, 19(2), 377-388. Diponible en: https://dx.doi.org/10.1590/S0102311X2003000800019

Aschieri, Patricia y Rodolfo Puglisi (2010). Cuerpo y producción de conocimiento en el trabajo de campo. Una aproximación desde la fenomenología, las ciencias cognitivas y las prácticas corporales orientales. En Silvia Citro (coord.), Cuerpos plurales. Ensayos antropológicos de y desde los cuerpos (pp. 127-148). Buenos Aires: Editorial Biblos.

Badinter, Elisabeth (1981). ¿Existe el instinto maternal? Barcelona: Paidós.

Barbetta, Pablo (2009). En los bordes de lo jurídico: conflictos por la tenencia legal de la tierra en Santiago del Estero (tesis de doctorado). Buenos Aires: Universidad de Buenos Aires.

Canevari, Cecilia (2011). Cuerpos enajenados. Experiencias de mujeres en una maternidad pública. Santiago del Estero: UNSE y Barco Edita.

Curiel, O. (2007). Crítica poscolonial desde las prácticas políticas del feminismo antirracista. Nómadas, 26, 92-101. Disponible en: http://www.redalyc.org/ $\mathrm{html} / 1051 / 105115241010 /$.

Dargoltz, Raúl (1997). El movimiento campesino santiagueño - MOCASE. Taller, 2(4), 27-32.

Da Silva, Cristiani Bereta (2004). Relações de gênero e subjetividades no devir MST. Estudos Feministas, 12(1), 269-287. https://doi.org/10.1590/S0104026X2004000100014

De Dios, Rubén (2009). Los campesinos santiagueños y su lucha por una sociedad diferente. Ponencia presentada en el I Congreso Nacional de Protesta Social, Acción Colectiva y Movimientos Sociales, Buenos Aires, 31 y 31 de marzo de 2009. Disponible en: http://www.iade.org.ar/uploads/beaee573-e871-0024.pdf 
Díaz Estévez, Pablo (2005). Resistencia campesina en Santiago del Estero. Informe final del concurso Poder y Nuevas Experiencias Democráticas en América Latina y el Caribe. Programa Regional de Becas CLACSO. Disponible en: http://biblioteca.clacso.edu.ar/ar/libros/becas/2005/demojov/diaz.pdf.

Di Liscia, Maria Herminia (2005). Dentro y fuera del hogar. Mujeres, familias y medicalización en Argentina, 1870-1940. Signos Históricos (13), 94-119. Disponible en: http://www.redalyc.org/html/344/34401305/.

Durand, Patricia (2006). Desarrollo rural y organización campesina en Argentina. El caso del Movimiento Campesino de Santiago del Estero (tesis de doctorado). Buenos Aires: Universidad de Buenos Aires.

Fonow, Margaret y Judith Cook (2005). Feminist Methodology: New applications in the academy and public policy. Signs: Journal of Women in Culture and Society, 30(40), 211- 236. https://doi.org/10.1086/428417

Furlin, Neiva (2013). A perspectiva de gênero no MST: um estudo sobre o discurso e as práticas de participação das mulheres. En Delma Neves y Leonilde Servolo de Medeiros (org.), Mulheres Camponesas: trabalho produtivo e engajamentos politicos (pp. 257-282). Niteroi: Alternativa.

Guber, Rosana (2011). La etnografía. Método, campo y reflexividad. Buenos Aires: Siglo XXI.

Hammersley, Martyn y Paul Atkinson (1994). Etnografia. Barcelona: Paidós.

Hays, Sharon (1998). Las contradicciones culturales de la maternidad. Barcelona: Paidós.

Jasper, James (2012). Las emociones y los movimientos sociales: veinte años de teoría e investigación. Revista Latinoamericana de Estudios sobre Cuerpos, Emociones y Sociedad, 4(10), 46-66.

Knibiehler, Yvonne (1997). La révolution maternelle: femmes, maternité, citoyenneté depuis 1945. París: Perrin.

Melucci, Alberto (1996). Challenging codes: Collective action in the information age. Cambridge: Cambridge University Press. https://doi.org/10.1017/ CBO9780511520891

Michi, Norma (2010). Movimientos campesinos y educación. El movimiento Sin Tierra y el movimiento campesino de Santiago del Estero-VC. Buenos Aires: El Colectivo.

Mies, María (1998). ¿Investigación sobre las mujeres o investigación feminista? El debate en torno a la ciencia y la metodología feministas. En Debates en torno a una metodología feminista, compilado por Eli Bartra (pp. 63-102). México, D. F.: Universidad Autónoma Metropolitana de México (Trad. Gloria Elena Bernal). 
Mohanty, Chandra ([1985] 2008). Bajo los ojos de occidente. Academia feminista y discurso colonial. En L. Suárez Navaz y A. Hernández (eds.), Descolonizando el feminismo: teorías y prácticas desde los márgenes (pp. 112-161). Madrid: Cátedra.

Movimiento Campesino de Santiago del Estero - Vía Campesina (MOCASE-VC) (2016) Memoria de los orígenes de la Central Campesina de Productores del Norte. Santiago del Estero: Movimiento Campesino de Santiago del Estero - Vía Campesina.

Murillo, Soledad (1996). El mito de la vida privada. Madrid: Siglo XXI.

Nari, María Marcela (2004). Las políticas de la maternidad y maternalismo político, Buenos Aires, 1890-1940. Buenos Aires: Biblos.

Oxman, Claudia (1998). La entrevista de investigación en ciencias sociales. Buenos Aries: Editorial Universitaria.

Palomar Verea, Cristina (2004). «Malas madres»: la construcción social de la maternidad. Debate feminista, 15(30), 12-34.

Paulilo, María Ignes (2009). Movimentos das mulheres agricultoras e os muitos sentidos da «igualdade de gênero». En Bernardo Fernandez, Leonilde Servolo de Medeiros, María Ignez Paulilo (org.), Lutas camponesas contemporâneas: condições, dilemas e conquistas: a diversidade das formas das lutas no campo (pp. 179-202). São Paulo: EDUNESP.

Pena, Mariela (2017a). Las políticas de la vida cotidiana en el Movimiento Campesino de Santiago del Estero-Vía Campesina, Argentina. Boletín de Antropología de la Universidad de Antioquia, 53, 210-231. https://doi.org/10.17533/udea.boan. v32n53a12

Pena, Mariela (2017b). Hacia una voz propia y feminista en el movimiento campesino de Santiago del Estero. Investigaciones Feministas de la Universidad Complutense de Madrid, 8(1), 245-266. https://doi.org/10.5209/INFE.53907

Pujadas, Juan José (2000). El método biográfico y los géneros de la memoria. Revista de Antropología Social, 9, 127-158.

Rapp, Rayna (1982). Family and classs in Contemporary América: notes toward an understanding of ideology. En Barrie Thorne y Maritye Yalom (comps.), Rethinking the family. Some Feminist Questions (pp.180-196). Nueva York: Longman.

Reinharz, Shulamit y Lynn Davidman (1992). Feminist Methods in Social Research. Nueva York: Oxford University Press.

Rubin, Jeffrey (1998). Ambiguity and Contradiction in a Radical Popular Movement. En Sonia Álvarez, Evelina Dagnino y Arturo Escobar (eds.), Cultures of politics/ politics of cultures: Re-visioning Latin American social movements (pp. 141-164). Boulder CO: Westview Press. https://doi.org/10.4324/9780429501135-8 
Vázquez Laba, Vanesa y Milena Páramo Bernal (2013). Mujeres subalternas ante los servicios de salud en la región noroeste argentino. Revista Electrónica Medicina, Salud y Sociedad, 3, 1-24 [serie en internet]. Disponible en: http://www.medicinasaludysociedad.com.

Wacheux, Frédéric (1996). Méthodes Qualitatives et Recherche en Gestion. París: Economica. 